\title{
Epidermal Growth Factor Receptor Distribution in Burn Wounds Implications for Growth Factor-mediated Repair
}

\author{
Barbara A. Wenczak, * John B. Lynch, * and Lillian B. Nanney * $\neq$ \\ Departments of * Plastic Surgery and ${ }^{\ddagger}$ Cell Biology, Vanderbilt University School of Medicine; \\ and ${ }^{\S}$ Research Service, Department of Veterans Affairs, Nashville, Tennessee 37232
}

\begin{abstract}
Epidermal growth factor (EGF) along with several related peptide growth factors has been shown both in vivo and in vitro to accelerate events associated with epidermal wound repair. EGF and transforming growth factor alpha act by binding to a common EGF receptor tyrosine kinase thereby initiating a series of events which ultimately regulate cell proliferation. This study examined the immunohistochemical localization of EGF receptor (EGF-R) in burn wound margins, adjacent proliferating epithelium, and closely associated sweat ducts, sebaceous glands, and hair follicles. Tissue specimens removed during surgical debridement were obtained from full and partial thickness burn wounds in 32 patients with total body surface area burns ranging from 2 to $88 \%$. In the early postburn period (days 2-4), prominent staining for EGF-R was found in undifferentiated, marginal keratinocytes, adjacent proliferating, hypertrophic epithelium, and both marginal and nonmarginal hair follicles, sweat ducts, and sebaceous glands. During the late postburn period (days 5-16), EGF-R was depleted along leading epithelial margins; however, immunoreactive EGF-R remained intensely positive in the hypertrophic epithelium and all skin appendages. Increased detection of immunoreactive EGF-R and the presence of $\left.{ }^{125} \mathrm{I}\right] \mathrm{EGF}$ binding in the hypertrophic epithelium correlated positively with proliferating cell nuclear antigen distributions. Thus, the presence of EGF-R in the appropriate keratinocyte populations suggests a functional role for this receptor during wound repair. Dynamic modulation in EGF receptor distribution during the temporal sequence of repair provides further evidence that an EGF/transforming growth factor alpha/EGF-R-mediated pathway is activated during human wound repair. (J. Clin. Invest. 1992. 90:2392-2401.) Key words: epidermal growth factor receptor $\bullet$ proliferating cell nuclear antigen • epidermis • growth factors • burns
\end{abstract}

\section{Introduction}

Numerous peptide growth factors such as epidermal growth factor $(E G F)^{1}(1,2)$, platelet-derived growth factor (3-5), basic fibroblast growth factor $(6,7)$, transforming growth factor $\beta$

Address correspondence to Lillian B. Nanney, Ph.D., Vanderbilt Medical Center, S-2221 MCN, Nashville, TN 37232.

Received for publication 23 October 1991 and in revised form 18 March 1992.

1. Abbreviations used in this paper: DAB, 3,3 diaminobenzidine; EGF, epidermal growth factor; EGF-R, EGF receptor; PCNA, proliferating cell nuclear antigen; TBSA, total body surface area; TGF $\alpha$ and $\beta$, transforming growth factor alpha and beta.

The Journal of Clinical Investigation, Inc.

Volume 90, December 1992, 2392-2401
(TGF $\beta),(8-11)$, and TGF $\alpha(12,13)$ have been shown to stimulate various aspects of wound healing. Indirect evidence suggests that several of these growth factors may exert their effects through modulation or binding to the EGF receptor (14-16). To date, the EGF receptor has been associated with key events connected with wound repair. In cultured cells, at least two basic reparative functions, cell motility and proliferation, are enhanced by the addition of EGF receptor ligands (TGF $\alpha$, EGF) to cultured cells $(17,18)$. In vivo, several studies using exogenous EGF and TGF $\alpha$ have proven effective for the acceleration of epithelialization in porcine and human wounds (2, $12,19)$. Since partial thickness burn wounds resurface by a process of epithelialization from both migrating and proliferating keratinocytes at wound margins and from viable hair follicles and sweat glands at the wound base, it has long been assumed (but not proven) that EGF receptors must be present during normal cellular proliferation which is an integral characteristic of healing wounds.

Epidermal growth factor and numerous related peptide growth factors such as TGF $\alpha$ (20), amphiregulin (21), macrophage-derived EGF-like peptide (22), tenascin (23), vaccinia virus growth factor (24) act by binding to a specific receptor known as the EGF receptor (EGF-R) (25). Experiments using cultured cells have shown that binding to the EGF receptor tyrosine kinase triggers a cascade of events which ultimately regulate cellular growth (26). The receptor for EGF-TGF $\alpha$ has previously been identified in normal human skin, primarily in basal keratinocytes of the epidermis and epidermal appendages such as hair follicles, sweat glands, and sebaceous glands (27, 28 ). The presence and distribution of EGF-R has been characterized under normal conditions of rapid proliferation which occur during fetal skin development (29). Likewise, increased EGF receptors have been linked with benign hyperproliferative epidermal diseases including psoriasis (30), seborrheic keratoses (31), as well as malignant neoplasia such as squamous cell carcinoma (32) and melanoma (33).

To begin to define endogenous mechanisms of growth factor-mediated repair, the presence of the EGF receptor was evaluated in healing wounds removed from burn patients. The temporal sequence and distribution for immunoreactive EGF$R$ was assessed in margins of partial thickness and full thickness burn wounds during the first $16 \mathrm{~d}$ of wound repair. The identification of the EGF receptor during the appropriate stages of wound repair suggests a direct mechanism involving this receptor and other known mediators of this receptor such as TGF $\beta$, platelet-derived growth factor, and protein kinase $C$ which may modulate EGF receptor expression or activity.

\section{Methods}

\section{Sample collection}

Human skin samples were collected from a total of 32 patients with either partial thickness or full thickness burns who underwent routine 
burn excision and autografting procedures at the Vanderbilt University Hospital Burn Center. The patients, 25 male and 7 female, ranged from 8 mo to 77 yr of age with total body surface area (TBSA) burns $2-88 \%$ as shown in Tables I and II. Tissue specimens were harvested from various body locations and were excised with a scalpel to subcutaneous fat or removed with a Zimmer dermatome where minimal specimen depth was 0.020 -inch in thickness. Specimens included a contiguous area of partial or full thickness burn wound and its adjacent healing epithelial margin. Specimens were immediately fixed in $4 \%$ paraformaldehyde for $24 \mathrm{~h}$ and embedded in paraffin.

\section{Reagents}

An anti-EGF-R serum was produced in rabbits from purified A-431 human epithelioid carcinoma cells as previously described $(34,35)$. The EGF-R antiserum has been previously shown to immunoprecipitate native, occupied, some precursor, and degradation forms of EGF$R$. Nonspecific sera from rabbits served as negative controls and normal epidermis and epidermal appendages in adjacent nonburned regions served as internal, positive controls. The three-step peroxidaseantiperoxidase procedure was performed with immunochemicals from a PAP kit purchased from DAKO, Inc. (Santa Barbara, CA). The 3,3-diaminobenzidine was supplied from Sigma Chemical Co. (St. Louis, MO). EGF was purchased from Collaborative Research (Waltham, MA) and [ ${ }^{125}$ I] EGF was obtained from New England Nuclear (Boston, MA). The autoradiography emulsion (NTB-2) was obtained from Eastman Kodak (Rochester, NY). Bovine serum and DMEM were purchased from Gibco Laboratories (Grand Island, NY). A monoclonal antibody to proliferating cell nuclear antigen (PCNA/ Cyclin) was purchased from Boehringer Mannheim Corp. (Indianapolis, IN). All other reagents were purchased from common suppliers and were of reagent grade.

\section{Localization of immunoreactive EGF receptor molecules}

Previously described immunohistochemical staining procedures for the identification of EGF-R were used for this study $(27,30,31,36$ 39). Paraffin-embedded tissues in 5- $\mu \mathrm{m}$ sections were placed onto gelcoated slides. Sections were deparaffinized through xylene, rehydrated through a graded series of ethanols, and preincubated in normal 3\% porcine serum for 20 min to saturate nonspecific tissue binding sites of serum components. Preimmune serum was blotted from the slides and the specimens were then incubated in either anti-EGF receptor serum (No. 451) or normal rabbit serum (No. 180). Both sera were diluted $1: 200$ in PBS containing 3\% porcine serum and glycine $(1 \mathrm{mg} / \mathrm{ml})$. All primary antibody incubations were performed overnight at $4^{\circ} \mathrm{C}$ in a humidified chamber. After incubation in the primary antibody, tissues were rinsed in PBS for 10 min and further incubated with the three-step immunoperoxidase procedure. Immunoreactive EGF-R was visualized using 3,3-diaminobenzidine (DAB) for the chromogen. The DAB was prepared using $0.05 \% \mathrm{DAB}$ in 0.05 Tris buffer at $\mathrm{pH} 7.6$ with $0.01 \% \mathrm{H}_{2} \mathrm{O}_{2}$ added before the reaction initiation. Sections were then rinsed in water, dehydrated, coverslipped, and photographed using an Olympus AH Vanox Light Microscope. Serial sections from all patients were stained with hematoxylin and eosin and histologically assessed for burn depth and tissue viability. Corresponding regions from burn wound and migrating epithelial margins from these serially sectioned hematoxylin and eosin slides were matched and photographed along with their immunostained companion slides. The intensity of immunoprecipitate in keratinocytes was scored by two independent observers using the following scale: + , receptors detectable with weak staining, ++ , receptors moderately stained, +++ , receptors intensely stained.

The most proximal, undifferentiated keratinocytes advancing under the nonviable scab have previously been characterized as the migrating population (40-45). In our study, the presumed "migrating" tip where keratinocytes were undifferentiated and nonstratified was $200-500 \mu \mathrm{m}$ in length with an average length equal to $316 \mu \mathrm{m}$ from the edge of the burn wound. The proliferative cell population was defined as the stratified, keratinized epidermis containing PCNA-labeled nuclei directly adjacent to the migrating cell population which did not contain PCNA-labeled nuclei.

\section{Control incubations}

Previously characterized positive specimens for immunoreactive EGF$\mathrm{R}$ were included in our immunohistochemical staining batches. Negative control specimens incubated with preimmune serum or purified IgG fractions all produced minimal levels of background staining. In all cases where regions of negative immunoreactivity were found on sections, adjacent areas of eccrine sweat ducts revealed positive immunoreactivity and thus served as internal semi-quantitative controls. In every case where negative immunoreactivity was detected in migrating epidermal edges, the immunohistochemical procedure was repeated on two separate occasions to ensure that the section was fully covered with antisera. These additional checks were also done to assess the reproducibility of the EGF-R distribution and to evaluate the relative staining intensities among different specimens.

\section{Localization of $\left[{ }^{125} I\right] E G F$ binding by autoradiography}

Experimental method. The localization of $\left[{ }^{125}\right.$ I]EGF by autoradiography in human skin sections was performed as previously described (27, $30,36)$. Skin samples were incubated for $90 \mathrm{~min}$ at $25^{\circ} \mathrm{C}$ with shaking in a medium consisting of $0.5 \mathrm{ml} \mathrm{HBSS}$ containing $1 \mathrm{mg} / \mathrm{ml} \mathrm{BSA}, 20$ $\mathrm{mM}$ Hepes at $\mathrm{pH} 7.4$, and $10 \mathrm{ng} / \mathrm{ml}\left[{ }^{125} \mathrm{I}\right]$ EGF. Unbound EGF was removed by repeated washes in the binding buffer at $25^{\circ} \mathrm{C}$. Reversibility testing was performed by first incubating some samples for $90 \mathrm{~min}$ in medium containing excess unlabeled EGF $(2 \mu \mathrm{g} / \mathrm{ml})$ after incubation with [ ${ }^{125}$ I] EGF. In control incubations, a 200 -fold excess of unlabeled EGF was included simultaneously with [ ${ }^{125}$ I] EGF to identify nonspecific radioactivity. All skin samples were fixed for $4 \mathrm{~h}$ in $10 \%$ neutral buffered formalin and processed for light microscopy in paraffin. Sections $(6-7 \mu \mathrm{m})$ were then dipped in an NTB-2 emulsion and exposed at $4^{\circ} \mathrm{C}$ for $8-10 \mathrm{wk}$. After development of the emulsion, the sections were lightly stained with hematoxylin and eosin. Photographs were then taken in both bright-field and dark-field illumination.

\section{Proliferating cell nuclear antigen immunohistochemistry}

Paraffin embedded human skin sections $(5 \mu \mathrm{m})$ were placed at $37^{\circ} \mathrm{C}$ overnight prior to deparaffinization in xylene and rehydration in ethanol and PBS (three times for $5 \mathrm{~min}$ each). Sections were then incubated with anti-PCNA (1:200) or normal (nonimmune) horse serum at $37^{\circ} \mathrm{C}$ for $60 \mathrm{~min}(46)$. After incubation with the primary antibody (anti-PCNA), tissues were rinsed with PBS for $15 \mathrm{~min}$ and then incubated with secondary antibody for $30 \mathrm{~min}$. After completion of the immunoperoxidase procedure, immunoreactive PCNA was visualized using DAB, rinsed in PBS, and stained with $1 \%$ nuclear fast red. Serial sections were then rinsed in water, coverslipped, and photographed in the same regions as the EGF-R immunostaining.

\section{Results}

\section{EGF receptors in the early postburn period}

Days 2-4. Epithelial margins surrounding partial and full thickness burn wounds were examined for the presence of the EGF receptor. A characterization of the patient population which was used for our evaluations during the early stages of wound repair is summarized in Table I and individually correlated with immunoreactive EGF-R in burn wound margins. Representative micrographs from the earliest phases of wound repair examined are displayed in Fig. 1, $A-H$.

On postburn day 2, EGF receptors were uniformly present in keratinocytes at the presumed migrating edge of epithelium in each of the three patients which were available at this early phase of healing. In contrast to the proximal, flattened, single cell layer of undifferentiated keratinocytes under the burn eschar, the epithelial cell population located more distal from the 

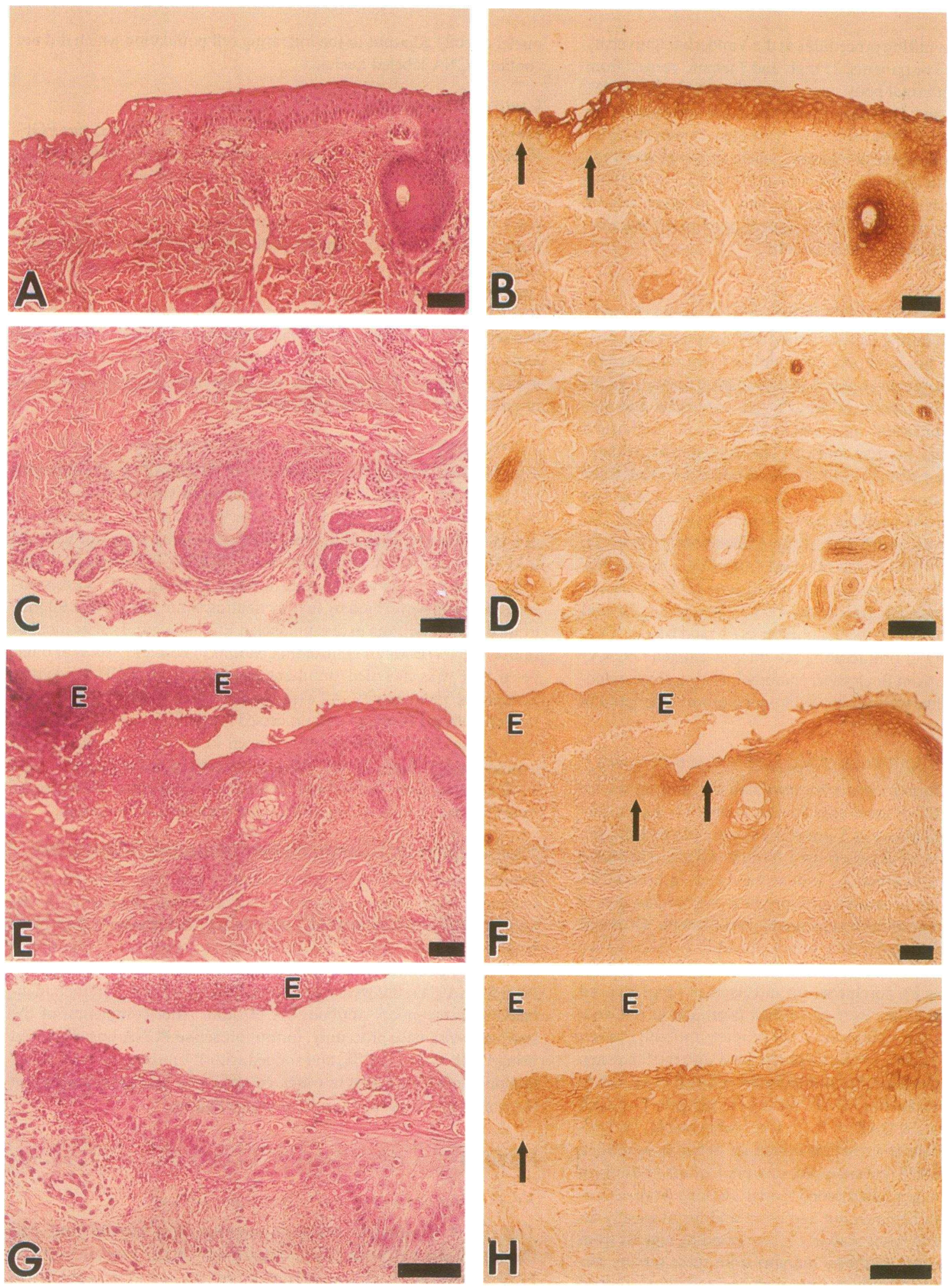

Figure 1. Early postburn period (days 2-4). Specimens were fixed in $4 \%$ paraformaldehyde and serial sections were stained with either hematoxylin and eosin $(A, C, E, G)$ or the EGF-R antiserum $(B, D, F, H)$ as described in Methods. Size bar $=100 \mu \mathrm{m}$. Arrows denote the migrating epithelial tip beneath burn eschar $(E)$. ( $A$ and $B$ ) On postburn day 2 in a 17 -yr-old patient with a $2 \%$ TBSA burn (Pt 1$)$, strong immunoreactivity for EGF-R is identified in the migrating epithelial tip (arrow) as well as in all cells of the nonburned hair follicle. No EGF-R immunoreactivity is present in the dermis. Keratinocytes in all layers of the proliferating epithelium adjacent to the burn wound stain uniformly positive for EGF-R. ( $C$ and $D)$ On postburn day 2 in a 17-yr-old patient with a $2 \%$ TBSA burn ( $\mathrm{Pt} 1$ ), viable keratinocytes from hair follicles in the deep dermis underneath the wound show EGF-R immunoreactivity as well as epithelial budding towards the surface. Immunostaining for EGF-R is also present in the double cuboidal epithelium of eccrine sweat ducts but not in dermal fibroblasts. $(E$ and $F$ ) On postburn day 3 in a 72 -yr-old patient with a 25\% TBSA burn ( $\mathrm{Pt} 9$ ), immunoreactive EGF-R are present in the migrating epithelial tip (arrows) advancing under burn eschar (e). Keratinoytes from a hair follicle and its associated sebaceous gland show weak yet positive EGF-R immunoreactivity. Adjacent hypertrophic epithelium shows EGF-R localization in the outer stratum spinosum and granulosum layers. ( $G$ and $H$ ) On postburn day 4 in a 30 -yr-old patient 
Table I. Early Postburn Period

\begin{tabular}{ccccllc}
\hline & & & & & & Migrating \\
Patient & Age & Sex & TBSA & Etiology & \multicolumn{1}{c}{ Site } & $\begin{array}{c}\text { Margin } \\
\text { EGF-R }\end{array}$ \\
\hline & $y r$ & & $\%$ & & & \\
PBD 2 & & & & & & \\
$(1)$ & 17 & M & 2 & Flame & Hand (dorsum) & ++ \\
$(2)$ & 20 & M & 9 & Tar & Thigh & +++ \\
$(3)$ & 32 & M & 25 & Flame & Chest & +++ \\
PBD 3 & & & & & & \\
$(4)$ & 25 & F & 1 & Grease & Forearm & ++ \\
$(5)$ & 30 & M & 18 & Flame & Forearm & NA \\
$(6)$ & 34 & M & 9 & Flame & Leg & +++ \\
$(7)^{*}$ & 50 & M & 34 & Flame & Thigh & + \\
$(8)$ & 52 & F & 20 & Grease & Thigh & ++ \\
$(9)^{*}$ & 72 & F & 25 & Flame & Back & +++ \\
$(10)$ & 73 & M & 21 & Flame & Thigh & + \\
$(11)$ & 47 & M & 15 & Flame & Thigh & +++ \\
PBD 4 & & & & & & \\
$(12)$ & 14 & M & 11 & Flame & Forearm & + \\
$(13)$ & 30 & F & 23 & Flame & Forearm & $++^{\ddagger}$ \\
$(14)$ & 49 & M & 23 & Flame & Forearm & ++ \\
$(15)$ & 73 & F & 10 & Flame & Forearm & ++ \\
& & & & & & \\
\hline
\end{tabular}

* Repeat skin samples from same patient.

₹ Patchy distribution of immunoreactive EGF-R.

NA, not available.

EGF-R Staining: weak, + ; moderate, ++ ; intense, +++ .

burn, contains numerous mitotic figures and consists of a well stratified epidermis. As early as $2 \mathrm{~d}$ after injury, this epidermis consisted of 10-15 cell layers, was beginning to become hypertrophic, and showed a distribution of EGF receptors throughout all layers (Fig. 1, $A$ and $B$ ) in the present study. Thus, our evaluations from the specimens from postburn day 2 suggest that EGF receptors were present in all epithelial cell layers both in the undifferentiated edge (Table I) and the hypertrophic surface epithelium.

Prominent immunoreactivity for EGF receptors was also detected on postburn day 2 in active hair follicles below the level of burn injury in partial thickness burn (Fig. 1, $C$ and $D$ ). Such marginal hair follicles are known to grow upward and contribute to the resurfacing of partial thickness burn wounds (Fig. 1, $B$ and $D$ ) (47). Definitive immunostaining for EGF receptors was identified in both the external and internal root sheath cells of hair follicles (Fig. $1 B$ ) and in their upward outgrowths (Fig. 1 D). The stratified, cuboidal epithelium of the viable portions of dermal sweat ducts showed marked immunostaining in the dermis beneath burn regions (data not shown ) and in the adjacent nonburned dermis (Fig. 1D). EGF receptor immunostaining was not detected in the cellular components of the dermis underneath partial thickness burn injuries or at the peripheral margin of full thickness burn wounds at any time post injury (Fig. $1, B, D, F$, and $H$ ).
On postburn day 3 in specimens from four patients (Table I), a slight decrease in immunostaining for EGF receptors was noted in migrating epidermal margins (Fig. $1 F$ ). Decreased immunoreactivity was observed in marginal hair follicles and sebaceous gland keratinocytes which when in a proliferative stage result in epidermal resurfacing (Fig. 1, $E$ and $F$ ). Burn eschar showed minimal background staining for EGF receptors (Fig. 1, $F$ and $H$ ) and was not considered to be positive when compared to negative control sections stained with normal rabbit serum. The weakest staining for EGF receptors in the leading epithelial tip was found in patients 7 and 10. Patient 7 was 50 yr old with a $34 \%$ TBSA burn and an inhalation injury while patient 10 was 73 yr old, hypoalbuminemic, and debilitated with a significant proportion of full thickness burn injury ( Table I). In all six patients evaluated on postburn day 3 , the basal epidermis adjacent to the migrating epithelial tip showed diminished immunoreactivity for EGF-R. In this location, immunoreactivity for EGF receptors was comparatively higher in the stratum granulosum layers although weak immunoreactivity was within detectable levels in the stratum germinativum (Fig. $1, E$ and $F$ ).

EGF receptors within migrating epithelial tips appeared to be slightly decreased on postburn day 4 (Fig. $1 H$ ) in three patients (Table I). Significantly decreased immunoreactivity for EGF-R was noted in a 14-yr-old patient (Pt 12) with a superficial $11 \%$ TBSA burn. Sweat ducts in all four patients showed strong EGF-R immunoreactivity. This intense staining for EGF-R in eccrine sweat ducts was a constant feature throughout all phases of wound healing and served as a convenient semi-quantitative positive control. In contrast, hair follicles showed moderate EGF-R immunoreactivity in patients 13-15 and weak immunoreactivity in patient 12 (data not shown) and were variably stained throughout wound healing.

\section{EGF receptors in late postburn period}

Days 5-16. Immunohistochemical data for EGF receptors is presented for the late postburn period in Fig. 2, $A-H$. A characterization of the patient population from this later stage of wound repair is summarized in Table II. On postburn day 5, staining for EGF receptors was decreased in the undifferentiated, marginal keratinocytes in five out of eight patients (Fig. $2 B$ ). In three of these eight patients, EGF receptor staining appeared patchy with focal areas of both weakly stained and intensely positive keratinocytes within the same migrating epithelial region (Table II); nevertheless, in these three patients, EGF receptor immunoreactivity remained intensely positive in eccrine sweat glands and dermal ducts adjacent to the burn wound margin (data not shown).

On postburn days $7,8,9,10,12$, and 16 (Table II), EGF receptors remained diminished in 12 patients with minimal positive staining in the epithelial tip (Fig. 2, $C$ and $D, E$ and $F$, $G$ and $H$ ). Only one exception to this staining pattern was noted ( $\mathrm{Pt} 37$ ) on postburn day 16 where immunoreactivity for EGF-R was strongly positive in the migrating epithelial tip ( Table II). As the process of reepithelialization continued during the late postburn period, the majority of marginal and nonmar-

with a 23\% TBSA burn ( $\mathrm{Pt} 13$ ), a diminished immunoreactivity for EGF-R is present in migrating epithelial cells (arrows). Basal keratinocytes in the proximal hypertrophic, proliferating epidermis still show prominent EGF- $R$ staining. Faint immunoreactivity for EGF-R is also present in some dermal cells. 

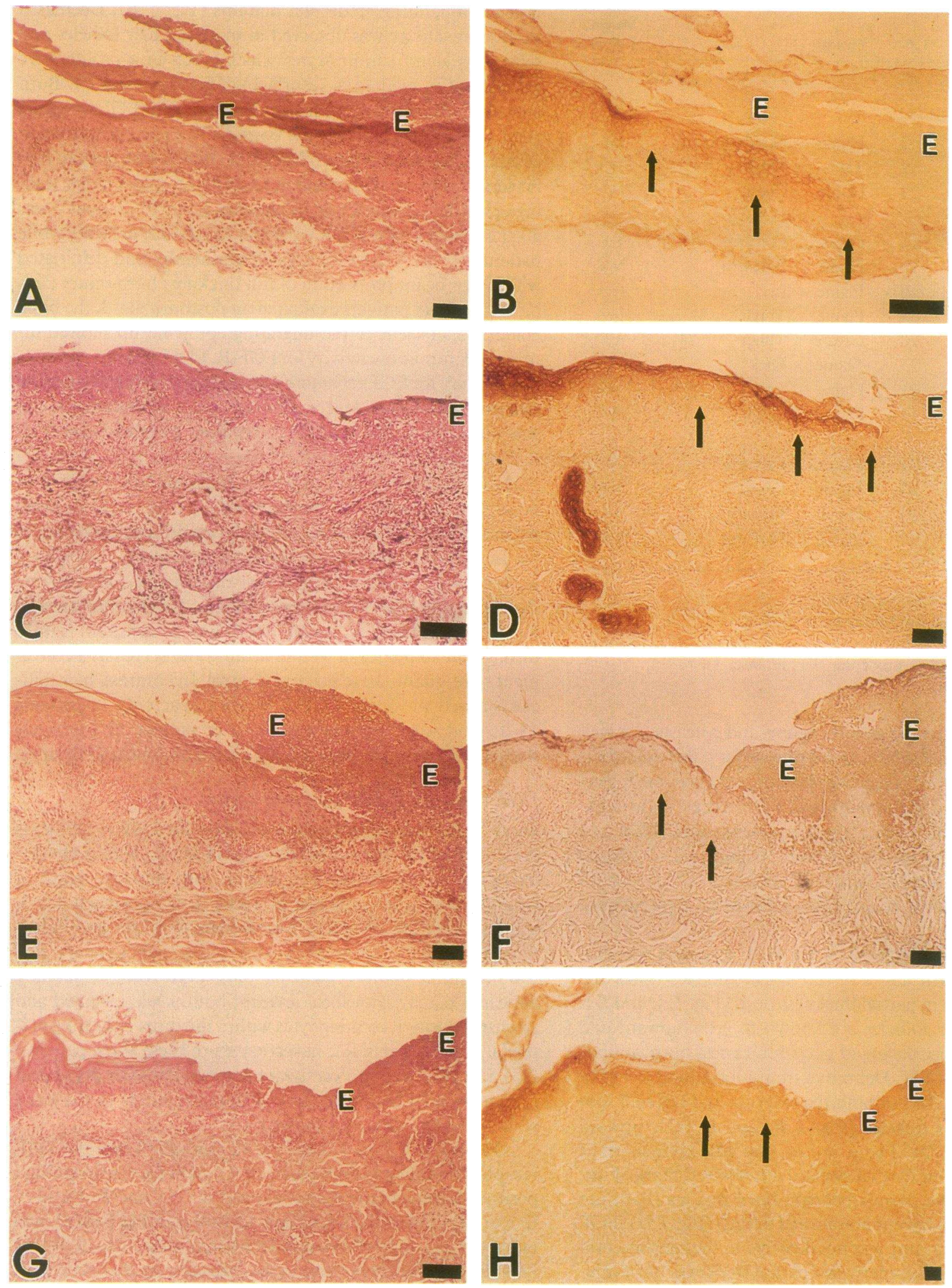

Figure 2. The later postburn period (days 5-10). Size bar $=100 \mu \mathrm{m}$. Arrows denote the migrating epithelial tip beneath burn eschar (E). $(A$ and $B$ ) At postburn day 5 in a 30-yr-old patient with a 15\% TBSA burn ( $\mathrm{Pt} 18$ ), the epithelial sheet migrating (arrows) under burn eschar (e) reveals a patchy staining pattern for EGF-R. Adjacent hypertrophic epithelium which contributes to the migrating sheet stains strongly positive for EGF-R in the outer stratum granulosum but somewhat less in the basal epidermis. ( $C$ and $D$ ) At postburn day 7 in a 77 -yr-old patient with a 9\% TBSA burn ( $\mathrm{Pt} 26$ ), diminished EGF-R staining is present in many of the keratinocytes in epithelial sheet migrating (arrows) under the eschar (e). In contrast, prominent immunoreactivity is present in the adjacent epidermis and an eccrine sweat duct. $(E$ and $F)$ At postburn day 
Table II. Late Postburn Period

\begin{tabular}{|c|c|c|c|c|c|c|}
\hline Patient & Age & Sex & TBSA & Etiology & Site & $\begin{array}{c}\text { Migrating } \\
\text { margin } \\
\text { EGF-R }\end{array}$ \\
\hline & $y r$ & & $\%$ & & & \\
\hline \multicolumn{7}{|l|}{ PBD 5} \\
\hline (16) & 5 & $\mathbf{M}$ & 2 & Flame & Leg & $++^{*}$ \\
\hline (17) & 26 & $\mathbf{M}$ & 35 & Flame & Leg & ++ \\
\hline (18) & 30 & $\mathrm{~F}$ & 15 & Flame & Forearm & ++ \\
\hline (19) & 35 & $\mathbf{M}$ & 16 & Flame & Back & $+++^{*}$ \\
\hline (20) & 54 & $\mathbf{M}$ & 39 & Flame & Forearm & $++^{*}$ \\
\hline$(21)^{\ddagger}$ & 56 & $\mathbf{M}$ & 55 & Flame & Thigh & ++ \\
\hline (22) & 60 & $\mathbf{M}$ & 4 & Flame & Hand (dorsum) & ++ \\
\hline$(23)^{\ddagger}$ & 64 & $\mathbf{M}$ & 32 & Flame & Arm & ++ \\
\hline \multicolumn{7}{|l|}{ PBD 7} \\
\hline$(24)$ & 31 & $\mathbf{M}$ & 28 & Flame & Back & + \\
\hline$(25)$ & 38 & $\mathbf{M}$ & 43 & Flame & Leg & + \\
\hline (26) & 77 & $\mathbf{M}$ & 9 & Flame & Chest & ++ \\
\hline$(27)^{\ddagger}$ & 64 & $\mathbf{M}$ & 47 & Flame & Thigh & ++ \\
\hline \multicolumn{7}{|l|}{ PBD 8} \\
\hline$(28)$ & $<1$ & $\mathbf{M}$ & 23 & Grease & Back & NA \\
\hline (29) & 3 & $\mathbf{M}$ & 17 & Flame & Chest & ++ \\
\hline$(30)^{\ddagger}$ & 32 & $\mathbf{M}$ & 88 & Flame & Chest & ++ \\
\hline$(31)^{\ddagger}$ & 50 & $\mathbf{M}$ & 34 & Flame & Back & + \\
\hline$(32)$ & 62 & $\mathbf{M}$ & 8 & Flame & Thigh & + \\
\hline \multicolumn{7}{|l|}{ PBD 9} \\
\hline$(33)^{\ddagger}$ & 72 & $F$ & 25 & Flame & Forearm & + \\
\hline (34) & 2 & $\mathrm{~F}$ & 19 & Scald & Thigh & ++ \\
\hline \multicolumn{7}{|l|}{ PBD 10} \\
\hline$(35)^{\ddagger}$ & 32 & $\mathbf{M}$ & 88 & Flame & Thigh & ++ \\
\hline \multicolumn{7}{|l|}{ PBD 12} \\
\hline$(36)$ & 31 & $\mathbf{M}$ & 17 & Flame & Chest & ++ \\
\hline \multicolumn{7}{|l|}{ PBD 16} \\
\hline (37) & 31 & $\mathbf{M}$ & 16 & Scald & Chest & +++ \\
\hline
\end{tabular}

* Patchy distribution of immunoreactive EGF-R.

${ }^{\ddagger}$ Repeat skin samples from same patient.

NA, not available.

EGF-R Staining: weak, + ; moderate, ++ ; intense, +++ .

ginal eccrine sweat glands, ducts, and hair follicles exhibited moderately positive staining for EGF receptors in 19 out of 22 patients. Exceptions were noted in patients 24,25 , and 36 ( Table II) where EGF receptors were diminished in sweat ducts which were directly contributing to the marginal epithelial cells. Similarly, hair follicles beneath proliferating epithelium showed decreased EGF receptors in these same patients. No immunostaining for EGF-R was detected in the fibroblast population at either the margin or in the underlying viable dermis of partial thickness burn wounds during days 5-16 in the 22 patients studied.

\section{Hypertrophic epithelium adjacent to burn wounds}

Morphologically, epithelium became visibly hypertrophic adjacent to migrating epithelial margins as early as postburn day 2 . Such proliferative or "activated" epidermis consisted of 2530 layers of keratinocytes with an expanded basal cell layer, prominent nucleoli and well developed rete ridges (Fig. 3). In hypertrophic epithelium on postburn days $2-5$, the EGF receptors were distributed in all nucleated cell layers with the most intense immunoreactivity for EGF-R in the spinous and granulosum cells (Fig. $3 C$ ). This distribution of EGF receptors was characteristic for 18 patients during the early and late postburn periods. Three exceptions were noted on postburn days 4 ( Pt 12), day 5 ( $\mathrm{Pt} 22$ ), and day 7 ( $\mathrm{Pt} 25$ ) (Tables I and II). In these specimens, EGF receptors were restricted to the basal and spinous cell layers resembling the previously reported basal distribution for EGF-R in normal adult human skin (27). Patient 12 was 14 yr old with a superficial partial thickness $11 \%$ TBSA burn and Pt 22 was 60 yr old with a $4 \%$ superficial partial thickness wound (Fig. 3, $A$ and $B$ ).

We were able to examine sequential EGF-R immunoreactivity during both the early and late postburn periods in a few patients who required surgical excision on separate occasions. An interesting phenomenon was observed in patient 21 . This 56-yr-old patient was an alcoholic with severe liver dysfunction who sustained a 55\% TBSA full thickness burn. Due to delayed wound healing and the need for multiple skin grafts, EGF-R immunoreactivity was studied on postburn days 5 (Table II) and 34 (Fig. $3 D$ ). On postburn day 34, EGF receptors in the hypertrophic epithelium over granulation tissue (neodermis) were distributed throughout the entire epidermis with moderate staining for EGF-R (Fig. $3 \mathrm{D}$ ).

\section{$\left[{ }^{125} I\right] E G F$ binding in epidermis}

To confirm the functional status of the EGF receptor using a different technique, the binding of $\left[{ }^{125} \mathrm{I}\right] \mathrm{EGF}$ in healing burn wound margins was evaluated on postburn day 5 . The density of silver grain deposition, indicating the location of unoccupied, available EGF receptor, was highest over the basal keratinocytes in the hypertrophic epithelium (Fig. $4 \mathrm{D}$ ). There was a progressive decrease in silver grain deposition over the stratum spinosum and granulosum with only background labeling in the stratum corneum. Moderate silver grain deposition was identified in the two to three cell layers of the flattened, undifferentiated epidermis immediately adjacent to the nonviable burn eschar (Fig. $4 B$ ). In experimental samples, low amounts of silver grains were seen in the dermis. However, in these same skin sections, extensive labeling for $\left[{ }^{125} \mathrm{I}\right] \mathrm{EGF}$ was identified in the pilosebaceous glands and in the sweat glands and ducts (data not shown). Most intense labeling in the hair follicle was localized to the outer root sheath cells (Fig. $4 \mathrm{~B}$ ). Control incubations were performed using a 200-fold excess of unlabeled EGF before or after incubation with [ $\left.{ }^{125} \mathrm{I}\right] \mathrm{EGF}$ to displace specifically bound $\left[{ }^{125} \mathrm{I}\right] \mathrm{EGF}$. The silver grain density remaining

7 in a 38 -yr-old patient with a $43 \%$ TBSA burn ( $P t$ 25), EGF-R immunoreactivity is noticeably absent in the migrating tip (arrows) and restricted to basal keratinocytes in the adjacent nonhypertrophic epithelium. Some nonspecific background staining is present in the burn eschar (e) and stratum corneum in this specimen. ( $G$ and $H$ ) At postburn day 10 in a 32-yr-old patient with an $88 \%$ TBSA burn (Pt 35), EGF-R staining is minimal in the migrating epithelial tip (arrows). In the adjacent epidermis, the most prominent immunostaining for EGF- $R$ is present in the stratum granulosum. 

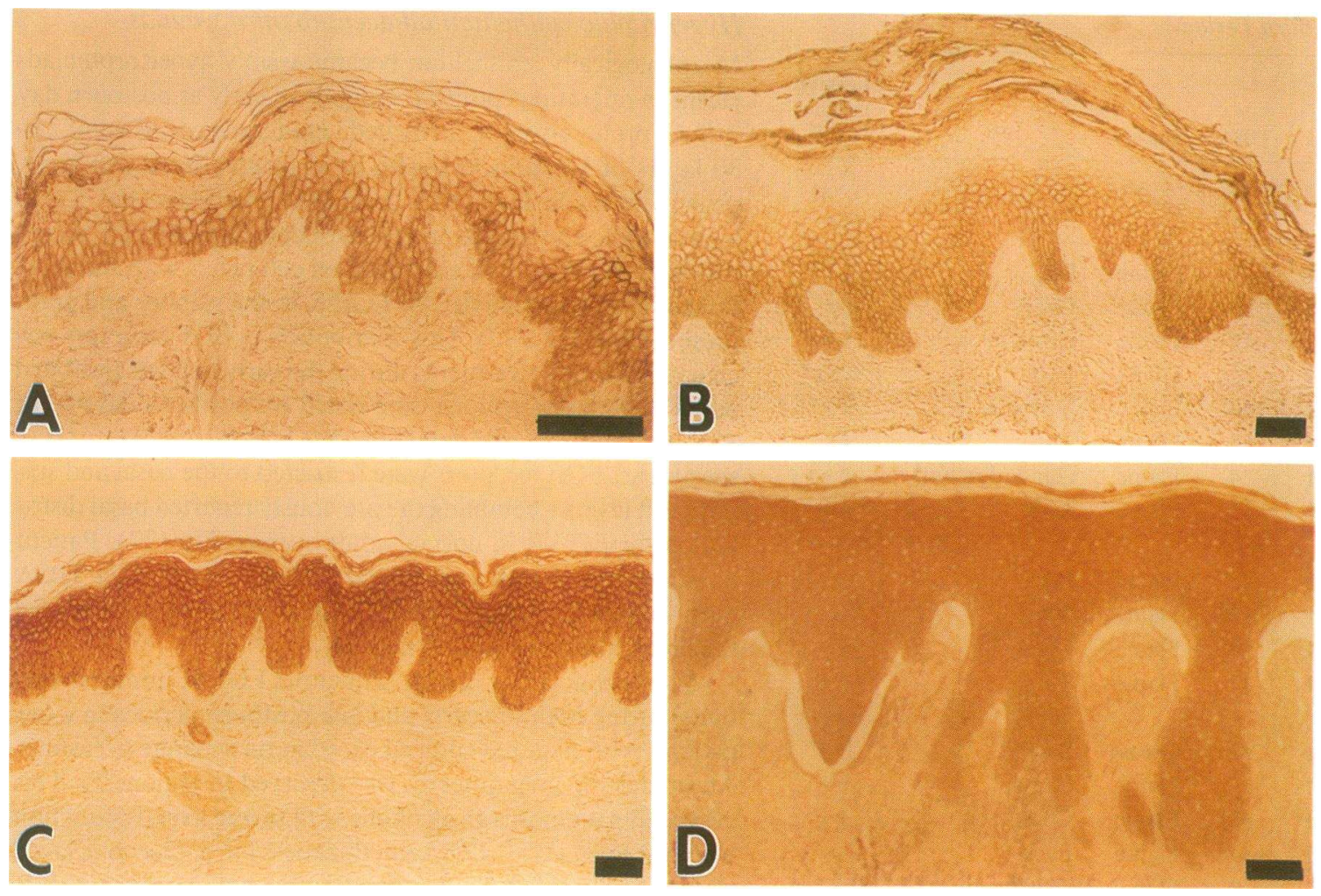

Figure 3. Hypertrophic epidermis adjacent to burn wounds. Size bar $=100 \mu \mathrm{m}$. (A) At postburn day 5 in a 60 -yr-old patient with a $4 \%$ TBSA burn (Pt 22), the EGF-R distribution is restricted to basal and spinous keratinocytes in the epidermis. ( $B$ ) At postburn day 7 in a 38 -yr-old patient with a $43 \%$ TBSA burn (Pt 25), the EGF-R are restricted to the basal and spinous cell layers in the later postburn period, but some nonspecific staining is noted in the stratum corneum. $(C)$ At postburn day 4 in a 49 -yr-old patient with a 23\% TBSA burn (Pt 14), intense EGF-R immunoreactivity is uniformly expressed in all layers of this epidermis bordering the injury during the early postburn period. Faint staining for EGF-R is present in fibroblasts in the dermis. $(D)$ At postburn day 34 in a 56-yr-old patient with a 55\% TBSA burn (Pt 21), moderate staining for EGF-R is displayed throughout the epidermis, but no immunoreactivity is present in the underlying dermis.

during these conditions was considered background radioactivity and remained negligible compared to experimental sections.

\section{Identification of proliferative epithelium by proliferating cell nuclear antigen}

Immunohistochemical localization of anti-PCNA was used to identify the proliferative cell population in epithelial margins and hypertrophic epithelium adjacent to partial and full thickness burn wounds. The density of anti-PCNA labeled nuclei was highest in the hypertrophic epithelium with intense localization in the basal keratinocyte nuclei with some labeling seen in the spinous cells. This density was significantly higher than anti-PCNA labeled nuclei observed in normal adult skin samples distant from the burn wound. As shown in Fig. $5 B$, antiPCNA labeled nuclei were increased compared to "normoproliferative" epidermis in the hypertrophic epithelium at postburn day 2 which represents the earliest time studied after injury. A high density of anti-PCNA labeled cells was present in all samples from all hypertrophic epidermis removed during the late postburn period. Anti-PCNA labeled nuclei were identified in the basal keratinocytes at the wound margin; however, undifferentiated, flattened keratinocytes advancing beneath burn eschar did not display the anti-PCNA marker as shown in Fig. $5 B$ and were therefore presumed to be the migrating population.

\section{Discussion}

Identification of EGF receptors in repairing burn wound epithelial margins suggests that EGF, TGF $\alpha$ or related peptides may play vital roles in wound repair after burn injury. Our results indicate that immunoreactive EGF receptors can be detected as early as $2 \mathrm{~d}$ after burn injury. During this early phase of wound repair, EGF receptors are concentrated in both the presumed migrating keratinocytes as well as in the proliferating basal keratinocytes of hypertrophic epithelium near neighboring wound margins. Since epidermal wound resurfacing in partial thickness burns depends heavily on epithelial cell proliferation and migration from viable skin appendages within the deep dermis, high concentrations of EGF-R which were uniformly present in epidermal appendages in regions adjacent to burn wounds further suggest that the availability of EGF-R may serve as a key regulatory factor during the initial period of epidermal repair.

The proliferative phase of wound repair commences, by definition, at the termination of tissue destruction 12-24 hours after burn injury (48). The development of hypertrophic epidermis adjacent to the migrating epithelial margin is visible evidence of the dramatic responses from uninjured epidermis. Intense localization of EGF-R in the basal, spinous, and granulosum layers of the hypertrophic epidermis especially in the early postburn period suggests that the requisite receptors for 

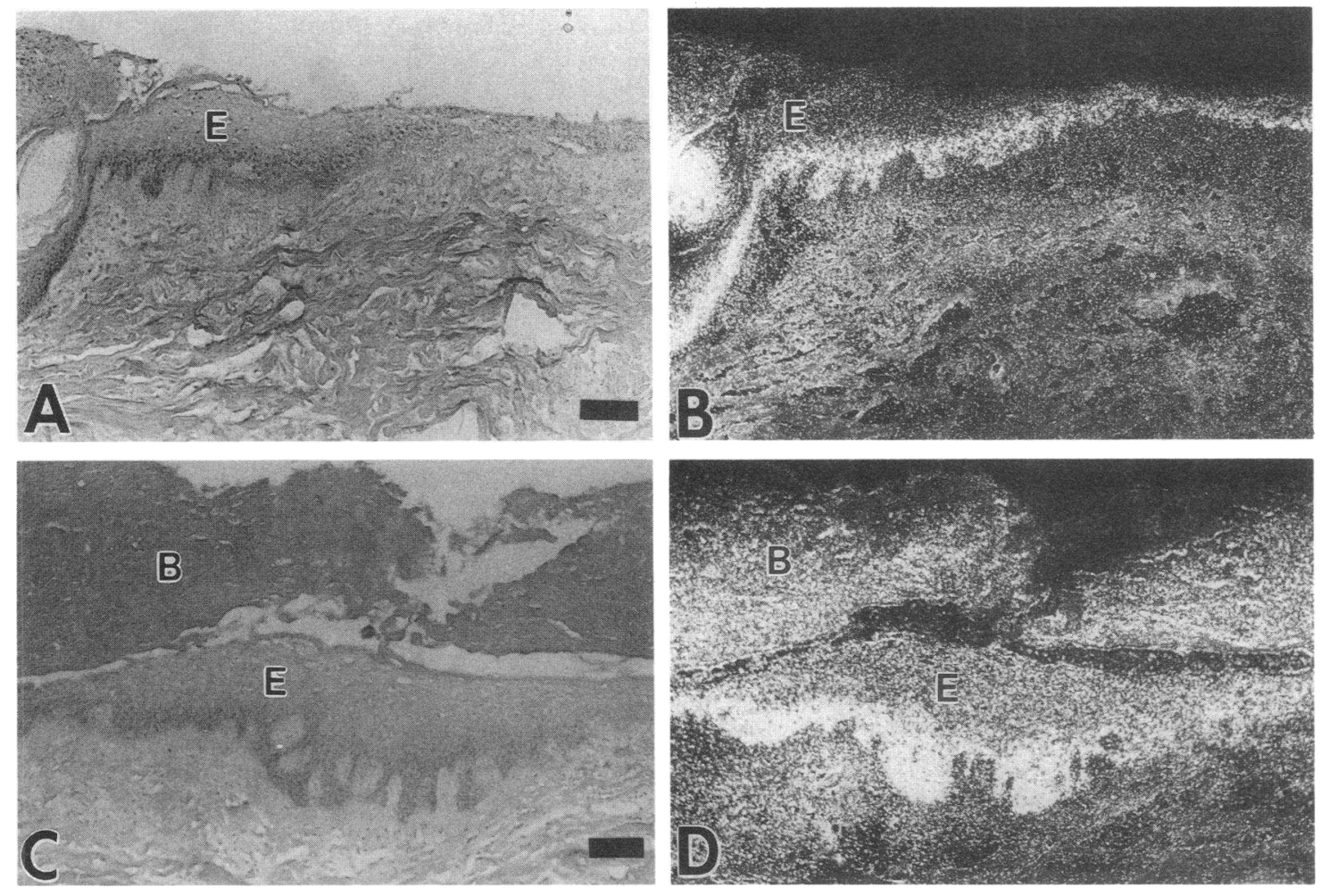

Figure 4. Autoradiograph of marginal epithelium and hair follicle ( $A$ and $B)$ and hypertrophic epithelium $(C$ and $D)$ adjacent to burn wound on postburn day 5. Tissues were incubated with [ $\left.{ }^{125} \mathrm{I}\right] \mathrm{EGF}$ as described in Methods and exposed for $6 \mathrm{wk}$. $(A)$ Light-field view of [ $\left.{ }^{125} \mathrm{I}\right] \mathrm{EGF}$ binding. Size bar $=100 \mu \mathrm{m} .(B)$ Corresponding dark-field view of $\left[{ }^{125} \mathrm{I}\right]$ EGF binding shows a high concentration of silver grains over the outer root sheath cells of the hair follicle and the basal epidermis. Reduced cell labeling is noted over the stratum granulosum and stratum corneum. $\mathrm{E}$, epidermis. $(C)$ Light-field view of hypertrophic epidermis. Size bar $=100 \mu \mathrm{m}$. $(D)$ Corresponding dark-field view of [ ${ }^{125}$ I] EGF binding shows increased deposition of silver grains in the basal and spinous cells of the hypertrophic epidermis. Decreased silver grains are noted in the stratum granulosum and in the overlying burn eschar $(B)$.

EGF and its related ligands are expressed in this proliferative cell population. Thus, the present study offers additional evidence of a direct EGF/TGF $\alpha /$ EGF-R pathway in human wound repair most probably responsive to endogenous ligands $(13,49-51)$ and/or transmodulation by other growth factors (14-16). Furthermore, the presence of EGF receptors at the appropriate phases of wound repair suggests that these receptors may be accessible and available for binding by exogenous ligands. Indeed, in vivo studies in a variety of wound healing situations including human trials have previously provided indirect evidence that application of exogenous EGF can accelerate wound resurfacing (19).

In the present study, the initial increase in EGF receptors in epidermal repair in the early postburn period is followed in the later stage of healing by an expected moderation in immunoreactive EGF-R in both the presumed migrating tip and the more distal hypertrophic epidermis. During the later phases of wound repair, the dynamic equilibrium of EGF receptors appears to shift toward downregulation as has been reported in cultured cells (52). The stimulus for this shift in the EGF-R equilibrium remains unknown; however, this declining availability of receptors may serve as a natural mechanism to limit growth factor mediated proliferation.

The decline of EGF receptors in burn wounds detected by immunolocalization of the receptor may represent translocation of the extracellular portion of the receptor occurring dur- ing different stages of wound repair. These findings are similar to previous clinical findings for the EGF receptor in various hyperproliferative epidermal skin disorders, where EGF receptors are markedly elevated in active lesions (30-33), but resume a restricted basal distribution as the disease process abates. This is the case in regressing lesions of seborrheic keratosis (31), acanthosis nigricans, and skin tags (33) as well as psoriasis vulgaris $(30,53)$.

As expected in any clinical study, exceptions were detected in both the localization of EGF receptors and their temporal sequence. We believe that these exceptions provide additional credence to the theory that EGF-R play an integral role in wound repair. Within our series of burn patients, three specimens were notable because they illustrate patients at opposite ends of the burn injury spectrum. The localization of EGF-R in basal/spinous keratinocytes in a 14-yr-old patient with an $11 \%$ total body surface burn on postburn day 4 and in another 38yr-old patient with a very superficial $43 \%$ total body surface area burn on postburn day 7 suggests that downregulation of EGF-R may be accelerated in either young patients or in those with minor burn injuries. At the opposite end of the spectrum was an older, severely burned, nutritionally compromised patient who was still struggling to heal on day 34. Although wound healing was extremely delayed in this case and still remained in the proliferative phase, EGF receptors were still detected within those slowly healing wounds. 

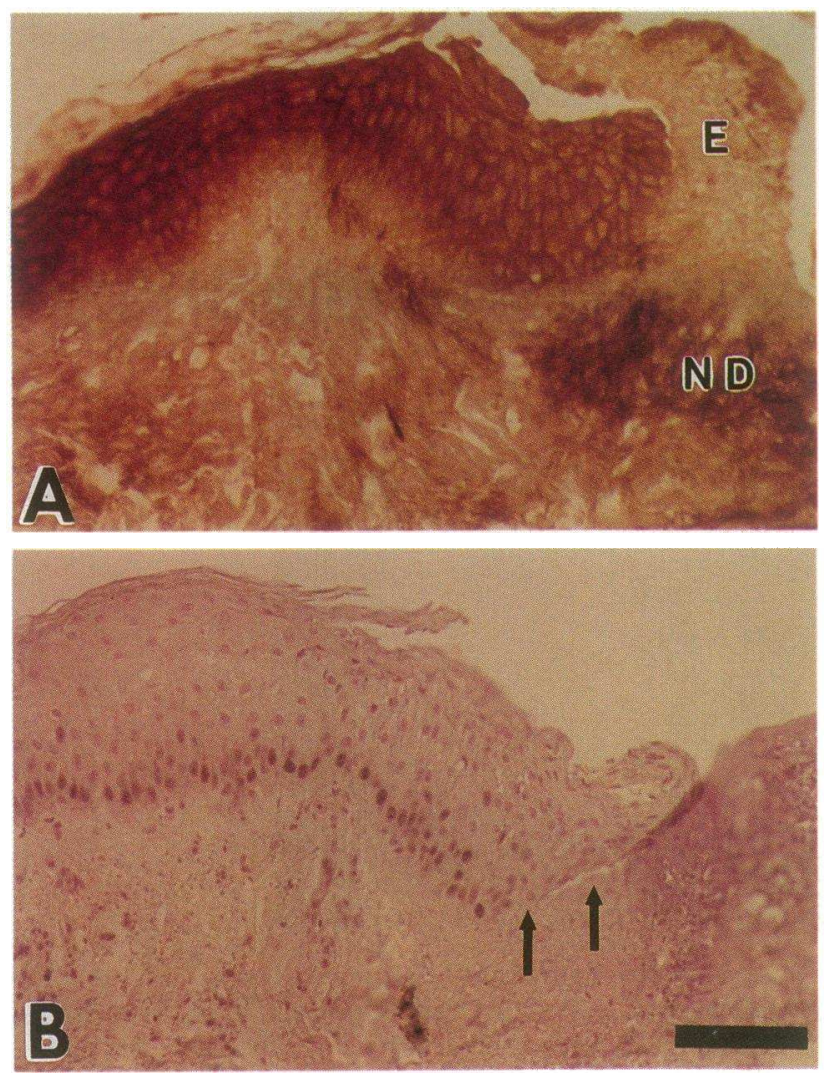

Figure 5. Comparison of EGF-R immunoreactivity and proliferating cell nuclear antigen in repairing epidermis. Arrows denote the migrating epithelial tip beneath burn eschar $(\mathrm{E})$. $(A)$ On postburn day 3 in a 47-yr-old patient with a $15 \%$ TBSA burn ( $P t 11$ ), EGF-R immunoreactivity is intense in all layers of the marginal epithelium as well as in the epithelial tip (arrow). Nonspecific staining was also noted in the adjacent nonviable dermis (ND). Viable dermal fibroblasts showed no staining for EGF-R. $(B)$ Corresponding marginal epithelium showing nuclei labeled with proliferating cell nuclear antigen. A predominance of labeled nuclei is localized to the basal cell layer and occasional labeled nuclei are seen in the spinous cell layer. PCNA-labeled nuclei are not observed in the marginal epithelial tip cells. Section counterstained with nuclear fast red to identify all nuclei in the basal cell layer. Size bar $=100 \mu \mathrm{m}$.

In this study, we have localized multiple forms of the EGF receptor in repairing burn wound margins. Detection of available EGF-R by extensive binding activity at postburn day 5 suggests that a significant portion of the EGF receptor is available on the extracellular surface of epithelial cells and free to reversibly bind circulating or exogenous EGF. Increased binding activity in the basal keratinocytes in the hypertrophic epithelium adjacent to repairing burn wound margins correlates well with the earlier identification of both [ ${ }^{125} \mathrm{I}$ ]EGF binding and immunoreactive EGF-R in the proliferative basal cell layer of normal adult human skin $(27,30)$. Additional characterization of PCNA-labeled nuclei in the hypertrophic epithelium has further confirmed active cell proliferation in the basal cells and occasionally some spinous cells during early and late phases of wound repair. Likewise, a depletion of EGF-R and the absence of identifiable proliferative capacity in the few undifferentiated epithelial cells at the most distal epithelial tip suggests that the EGF receptor may have a multifunctional role in the regulation of epithelial wound repair.

These data suggest that the presence of the EGF receptor is a common denominator in the wound healing process after burn injury. When coupled with the clinical evidence of acceleration of reepithelialization following exogenous application of EGF (19), our findings suggest an endogenous growth factormediated pathway during wound repair that may be amenable to exogenous manipulation.

\section{Acknowledgments}

We are grateful for the expert technical assistance of Jesse Britton, Fannie Burton, Nancy Cardwell, and Lise McLean.

This work was supported by funds from the Plastic Surgery Department (B. A. Wenczak), National Institutes of Health GM40437 (L. B. Nanney), and the Department of Veterans' Affairs (L. B. Nanney).

\section{References}

1. Brown, G. L., L. Curtsinger, J. R. Brightwell, D. M. Ackerman, G. R. Tobin, H. C. Polk, C. George-Nascimanto, P. Valenzuela, and G. Schultz. 1986. Enhancement of epidermal regeneration by biosynthetic epidermal growth factor. J. Exp. Med. 163:1319-1324.

2. Nanney, L. B. 1990. Epidermal and dermal effects of epidermal growth factor during wound repair. J. Invest. Dermatol. 94:624-629.

3. Grotendorst, G. R., G. R. Martin, D. Poncer, J. Sodek, and A. K. Harvey. 1985. Stimulation of granulation tissue formation by platelet-derived growth factor in normal and diabetic rats. J. Clin. Invest. 76:2323-2329.

4. Lynch, S. E., J. C. Nixon, R. B. Colvin, and H. N. Antoniades. 1987. The role of platelet-derived growth factor in wound healing: synergistic effects with other growth factors. Proc. Natl. Acad. Sci. USA. 84:7696-7700.

5. Antoniades, H. N., T. Galanopoulos, J. Nevill-Golder, C. P. Kiritsy, and S. E. Lynch. 1991. Injury induces in vivo expression of platelet-derived growth factor (PDGF) and PDGF receptor mRNAs in skin epithelial cells and PDGF mRNA in connective tissue fibroblasts. Proc. Natl. Acad. Sci. USA. 88:565-569.

6. Broadley, K. N., A. M. Aquino, S. C. Woodward, A. Stuvock, Y. Sato, D. B. Rifkin, and J. M. Davidson. 1989. Monospecific antibodies indicate that basic fibroblast growth factor is intrinsically involved in wound repair. Lab. Invest. 61:571-575.

7. Hebda, P. A., C. K. Klingbeil, J. A. Abraham, and J. C. Fiddes. 1990. Basic fibroblast growth factor stimulation of epidermal wound healing in pigs. J. Invest. Dermatol. 95:626-631.

8. Pierce, G. F., T. A. Mustoe, J. Lingelbach, V. Masakowski, P. Gramates, and T. F. Deuel. 1989. Transforming growth factor $\beta$ reverses the glucocorticoidinduced wound healing deficit in rats and is regulated by platelet derived growth factor in macrophages. Proc. Natl. Acad. Sci. USA. 86:2229-2233.

9. Quaglino, D., L. B. Nanney, R. Kennedy, and J. M. Davidson. 1990 Transforming growth factor- $\beta$ stimulates wound healing and modulates extracellular matrix gene expression in pig skin: excisional wound model. Lab. Invest. 63:307-319.

10. Quaglino, D., L. B. Nanney, R. Kennedy, and J. M. Davidson. 1991. Transforming growth factor $\boldsymbol{\beta}$ stimulates wound healing and modulates extracellular matrix gene expression in pig skin: incisional wound model. J. Invest. Dermatol. 97:34-42.

11. Pierce, G. F., J. V. Berg, R. Rudolph, J. Tarpley, and T. A. Mustoe. 1991. Platelet-derived growth factor-BB and transforming growth factor beta-1 selectively modulate glycosaminoglycans, collagen, and myofibroblasts in excisional wounds. Am. J. Pathol. 138:629-646.

12. Schultz, G. S., M. White, R. Mitchell, G. Brown, J. Lynch, D. R. Twardzik, and G. J. Todaro. 1987. Epithelial wound healing enhanced by transforming factor- $\alpha$ and vaccinia growth factor. Science (Wash. DC). 235:350-352.

13. Rappolee, D. A., D. Mark, M. J. Banda, and Z. Werb. 1988. Wound macrophages express TGF- $\alpha$ and other growth factors in vivo: analysis by mRNA phenotyping. Science (Wash. DC). 241:708-712.

14. Massague, J. 1985. Transforming growth factor beta modulates the high affinity receptors for epidermal growth factor and transforming growth factor alpha. J. Cell Biol. 100:1500-1514.

15. Olashaw, N. E., E. J. O'Keefe, and W. J. Pledger. 1986. Platelet-derived growth factor modulates epidermal growth factor receptors by a mechanism distinct from that of phorbol esters. Proc. Natl. Acad. Sci. USA. 83:3834-3839.

16. Sporn, M. B., and A. B. Roberts. 1988. Peptide growth factors are multifunctional. Nature (Lond.). 332:217-218. 
17. Barrandon, Y., and H. Green. 1987. Cell migration is essential for sustained growth of keratinocyte colonies: the roles of transforming growth factor- $\alpha$ and epidermal growth factor. Cell. 50:1131-1137.

18. Hebda, P. A. 1988. Stimulatory effects of TGF- $\beta$ and EGF on epidermal cell outgrowth from porcine skin explant cultures. J. Invest. Dermatol. 91:440445 .

19. Brown, G. L., L. B. Nanney, J. Griffin, A. Cramer, J. M. Yancey, L. J. Curtsinger, L. Holtzin, G. S. Schultz, M. J. Jurkiewicz, and J. B. Lynch. 1989. Enhancement of wound healing by topical treatment with epidermal growth factor. N. Engl. J. Med. 321:76-79.

20. Derynck, R. 1986. Transforming growth factor-alpha: structure and biological activities. J. Cell. Biochem. 32:293-304.

21. Shoyab, M., G. D. Plowman, V. L. McDonald, J. G. Bradley, and G. J. Todaro. 1989. Structure and function of human amphiregulin: a member of the epidermal growth factor family. Science (Wash. DC). 243:1074-1076.

22. Higashiyama, S., J. A. Abraham, J. Miller, J. C. Diffes, and M. Klagsbrun. 1991. A heparin-binding growth factor secreted by macrophage-like cells that is related to EGF. Science (Wash. DC). 251:936-939.

23. Taylor, H. C., V. A. Lightner, W. F. Beyer, D. McCaslin, G. Briscoe, and H. P. Erickson. 1989. Biochemical and structural studies of tenascin/hexabrachion proteins. J. Cell. Biochem. 41:71-90.

24. Brown, J. P., D. R. Twardzik, H. J. Marguardt, and G. J. Todaro. 1985. Vaccinia virus encodes a polypeptide homologous to epidermal growth factor and transforming growth factor. Nature (Lond.). 313:491-492.

25. Carpenter, G., and M. I. Wahl. 1990. The epidermal growth factor family. In Handbook of Experimental Pharmacology. Peptide Growth Factors and their Receptors. M. B. Sporn and A. B. Roberts, editors. Springer-Verlag, New York. Vol. 95, Chap. 4.

26. Carpenter, G., and S. Cohen. 1990. Epidermal growth factor-minireview. J. Biol. Chem. 265:7709-7712.

27. Nanney, L. B., C. M. Stoscheck, and L. E. King. 1984. Comparison of epidermal growth factor binding and receptor distribution in normal human epidermis and epidermal appendages. J. Invest. Dermatol. 83:385-393.

28. Green, M. R., and J. R. Couchman. 1985. Differences in human skin between the epidermal growth factor receptor distribution detected by EGF binding and monoclonal antibody recognition. J. Invest. Dermatol. 85:239-245.

29. Nanney, L. B., C. M. Stoscheck, L. E. King, R. A. Underwood, and K. A. Holbrook. 1990. Immunolocalization of epidermal growth factor receptors in normal developing human skin. $J$. Invest. Dermatol. 94:742-748.

30. Nanney, L. B., C. M. Stoscheck, M. Magid, and L. E. King. $1986 .{ }^{125} \mathrm{I}$-Epidermal growth factor binding and receptor distribution in psoriasis. 1986. $J$. Invest. Dermatol. 86:260-265.

31. Ellis, D. L., L. B. Nanney, and L. E. King. 1990. Increased EGF receptors in seborrheic keratoses and acrochordons of dysplastic nevus syndrome patients. J. Am. Acad. Dermatol. 23:1070-1077.

32. Ozanne, B., C. S. Richards, R. Hendlen, D. Burns, and B. Gusterson. 1986. Overexpression of the EGF receptor is a hallmark of squamous cell carcinomas. J. Pathol. 149:9-14.

33. Ellis, D. L., S. P. Kafka, J. C. Chow, L. B. Nanney, W. H. Inman, M. E. McCadden, and L. E. King. 1987. Melanoma, growth factors, acanthosis nigricans, the sign of Leser-Trelat, and multiple acrochordons: a role for transforming growth factor-alpha in cutaneous paraneoplastic syndromes. N. Engl. J. Med. 317:1582-1587.

34. Stoscheck, C. M., and G. Carpenter. 1983. Characteristics of antibodies to the epidermal growth factor receptor-kinase. Arch. Biochem. Biophys. 227:457468.

35. Stoscheck, C. M. 1986. Characteristics and uses of antibodies to the EGFreceptor kinase. J. Cell. Biochem. 31:135-152.

36. Magid, M., L. B. Nanney, C. M. Stoscheck, and L. E. King. 1985. Epidermal growth factor binding and receptor distribution in term human placenta. Placenta. 6:519-526.

37. Werner, M. H., L. B. Nanney, C. M. Stoscheck, and L. E. King. 1988. Localization of immunoreactive epidermal growth factor receptors in human nervous system. J. Histochem. Cytochem. 36:81-86.

38. Nanney, L. B., C. M. Stoscheck, and L. E. King. 1988. Characterization of binding and receptors for epidermal growth factor in smooth muscle. Cell Tissue Res. 254:125-132.

39. Birecree, E., W. O. Whetsell, C. M. Stoscheck, and L. E. King. 1988. Immunoreactive epidermal growth factor receptors in neuritic plaques from patients with Alzheimer's Disease. J. Neuropathol. Exp. Neurol. 47:549-560.

40. Arey, L. B. 1936. Wound healing. Physiol. Rev. 16:327-406

41. Odland, G., and R. Ross. 1968. Human wound repair. I. Epidermal regeneration. J. Cell Biol. 39:135-168.

42. Bullough, W. S. 1969. Epithelial repair. In Repair and Regeneration, the Scientific Basis for Surgical Practice. J. E. Dunphy and W. Van Winkle, editors. McGraw-Hill Inc., New York. 35.

43. Giacometti, L., and W. Montagna. 1969. Healing of skin wounds in primates. In Repair and Regeneration, the Scientific Basis for Surgical Practice. J. E. Dunphy and W. Van Winkle, editors. McGraw-Hill Inc., New York. 47.

44. Winter, G. D. 1972. Epidermal regeneration studies in the domestic pig. In Epidermal Wound Healing. H. T. Maibach and D. T. Rovee, editors. Yearbook Medical Publishers, Chicago. 71-112.

45. Krawczyk, W. S. 1971. Pattern of epidermal cell migration during wound healing. J. Cell Biol. 49:247-263.

46. Thaete, L. G., D. J. Ahnen, and A. M. Malkinson. 1989. Proliferating cell nuclear antigen (PCNA/Cyclin) immunocytochemistry as a labeling index in mouse lung tissues. Cell Tissue Res. 256:167-173.

47. Van Winkle, W. 1968. The epithelium in wound healing. Surg. Gynecol. \& Obstet. 127:1089-1115.

48. deCamara, D. L., T. J. Raine, M. D. London, M. C. Robson, and J. P. Heggers. 1982. Progression of thermal injury: a morphologic study. Plast. Reconstr. Surg. 69:491-499.

49. Coffey, R. J., Jr., R. Derynck, J. N. Wilcox, T. S. Bingman, A. S. Goustin, H. L. Moses, and M. R. Pittelkow. 1987. Production and auto-induction of transforming growth factor $\alpha$ in human keratinocytes. Nature (Lond.). 328:817-820.

50. Gottlieb, A. B., C. K. Chang, N. D. Posnett, and J. P. Tam. 1988. Detection of TGF $\alpha$ in normal, malignant and hyperproliferative human keratinocytes. J. Exp. Med. 167:670-675.

51. Finzi, E., R. Harkins, and T. Horn. 1991. TGF $\alpha$ is widely expressed in differentiated as well as hyperproliferative skin epithelium. J. Invest. Dermatol. 96:329-332.

52. Carpenter, G., and S. Cohen. 1976. ${ }^{125}$ I-Labelled human epidermal growth factor. Binding, internalization and degradation in human fibroblasts. $J$. Cell Biol. 71:159-171.

53. Nanney, L. B., R. A. Yates, J. Chow, and L. E. King. 1992. Modulation of epidermal growth factor receptors (EGF-R) during treatment with topical EGF. J. Invest. Dermatol. 98:296-301. 